\title{
Infections in Children with Newly Diagnosed Idiopathic Nephrotic Syndrome
}

\section{Shanjoy Kumar Paul ${ }^{1 *}$ \\ Quazi Rakibul Islam \\ Golam Muin Uddin ${ }^{2}$ \\ M Moazzam Hossain ${ }^{3}$}

'Department of Pediatric Nephrology

Sir Salimullah Medical College

Dhaka, Bangladesh.

${ }^{2}$ Department of Pediatric Nephrology Bangabandhu Sheikh Mujib Medical University Dhaka, Bangladesh.

${ }^{3}$ Professor \& Ex-Chairman

Department of Pediatric Nephrology

Bangabandhu Sheikh Mujib Medical University Dhaka, Bangladesh.
*Correspondence to:

\section{Dr. Shanjoy Kumar Paul}

Associate Professor

Department of Pediatric Nephrology

Sir Salimullah Medical College

Mitford, Dhaka

Bangladesh.

Cell: +88-01716330978

E-mail:drshanjoy@gmail.com,

shanjoykumarpaul@yahoo.com.au

\begin{abstract}
Patients with nephrotic syndrome (NS) are susceptible to different types of bacterial, viral \& fungal infections. This prospective observational study was performed in the Pediatric Nephrology unit of Bangabandhu Sheikh Mujib Medical University, Dhaka from January, 2006 to May, 2008 to determine the types of infection associated with initial attack of idiopathic NS and to alert the physicians about this so that they can take preventive and therapeutic measures more promptly. 112 admitted children aged one to fifteen years with first attack of idiopathic NS were included. After control of existing infection, prednisolone was given in recommended dose \& duration. All patients were followed for development of any type of new infection up to completion of treatment. Mean age was 61.87 months \& male female ratio was 1.49:1. Most patients $(78.57 \%)$ had been suffering from different types of infection on admission with male preponderence $(59.09 \%) \&$ most were under-6 years old $(67.04 \%)$. During prednisolone therapy, $29.46 \%$ patients developed infections, $63.64 \%$ were male and under- 6 years old were $72.73 \%$. Fever, cough, abdominal pain \& loose motion were the commonest presentations related to infection. Acute respiratory infection (ARI), acute watery diarrhea \& urinary tract infection (UTI) were the most common infections on admission $(53.57 \%, 34.82 \%$, and $7.14 \%$ respectively). ARI \& oral thrush were commonest infections during treatment with prednisolone (14.27\% \& $12.50 \%$ respectively). Infection should be ruled out carefully in every case of NS at each visit and during management in hospital \& outside to reduce morbidity \& mortality.
\end{abstract}

Key words: Infection; Children; Nephrotic syndrome.

\section{INTRODUCTION}

NS is a common kidney disease in children. These patients are susceptible to different types of bacterial, viral \& fungal infections and infections may trigger the disease or relapse or cause steroid resistance ${ }^{1}$. Abnormalities in the functions of the $\mathrm{T}$ lymphocytes and in particular the suppressor $\mathrm{T}$ lymphocytes and the generation of circulating factors capable of altering the glomerular permeability to proteins seem to be involved in the pathogenesis of the disease ${ }^{2}$. The infectious episodes result from a group of alterations that synergically increase the patients' susceptibility to infections. These alterations are low serum levels of immunoglobulins, particularly $\mathrm{IgG}$, due fundamentally to low production and to a lesser extent to catabolism and renal losses; defect in the opsonization of bacteria; and immunosuppressive therapy $^{3.4}$. Infectious episodes in nephrotic patients are responsible for high morbidity and can also cause an inadequate response to corticosteroid therapy and recurrences among patients in remission ${ }^{5}$. Determining the type of infection is important, not only from the therapeutic point of view, but also to establish preventive measures ${ }^{6}$. The objective of the study was to determine the types of infection associated with idiopathic nephrotic syndrome (INS) and to alert the physicians about this so that they can take preventive and therapeutic measures more promptly. 


\section{MATERIALS AND METHODS}

Study design: Prospective observational study

Place of study: Pediatric Nephrology unit, Department of Pediatrics, Bangabandhu Sheikh Mujib Medical University (BSM M U), D haka, B angladesh

Period of study: From J anuary, 2006 to M ay, 2008

Study population: One year to fifteen years aged children suffering from $1^{\text {st }}$ attack of INS

Sample size: 115 children suffering from initial attack of INS Sampling method: A II children admitted with $1^{\text {st }}$ attack of INS

Inclusion C riteria

1. A ge: 1 year to 15 years of both sexes

2. Who responded within 4 weeks of prednisolone therapy

3. Who successfully completed the treatment regimen

Exclusion C riteria

1. Steroid- resistant nephrotic syndrome

2. Secondary nephrotic syndrome

3. A ge bel ow 1 year and more than 15 years

4. NS patients who required injection methyl prednisolone in initial attack

5. NS with impaired renal function, macroscopic hematuria, uncontrolled hypertension and congenital renal anomalies

Methodology: After diagnosis of initial attack of INS by clinical features and standard laboratory investigations, written consent was taken from father or mother or caregiver of the patient. Any existing infection was diagnosed from sign/symptom and supporting investigations. Patients were given prednisolone in recommended doses $\&$ duration for $1^{\text {st }}$ attack. Patients were followed up to completion of treatment of first attack to see the presence of any infection.

Initial evaluation included urine for routine \& microscopic examination, culture sensitivity and colony count, 24 hours urinary total protein or spot urine protein-creatinine ratio whichever possible, chest X-ray P-A view, ultrasonogram of kidney- ureter- bladder region, complete blood count with ESR $\&$ peripheral blood film, blood urea level, serum creatinine level, serum cholesterol level, serum albumin level, HBsA g and any relevant investigation if necessary (e.g. blood culture, ascitic fluid study, $M$ antoux test).

Weight of the patients was measured in $\mathrm{kg}$ by bath scale. Height was measured in $\mathrm{cm}$ by a scale attached to the wall in the ward and out-patient follow- up room. Blood pressure was measured by aneroid sphygmomanometer. Hypertension was defined if systolic or diastolic blood pressure was $>95$ th percentile for age, sex and height which was confirmed on at least two measurements. Proteinuria was diagnosed by bed-side urine examination (heat coagulation test) every morning.

Follow-up was done at the end of treatment of $1^{\text {st }}$ attack and during treatment period if needed.

Those who expired, discontinued treatment or took prolonged prednisolone other than recommendation were excluded from study.

Data Collection: Data was collected in a predefined data collection sheet.

Data Analysis: Collected data was analyzed manually after completion of treatment of first attack. U nivariate tables were prepared when indicated.

Ethical consideration: Written consent was taken from the parents/guardians of the patients. Ethical clearance was taken from the ethical committee of BSM MU.

\section{RESULTS}

Out of 115 patients, three were excluded from study due to different reasons. One patient $(0.89 \%)$ died of chicken pox before starting treatment with prednisolone. One patient discontinued treatment $\&$ another took prolonged prednisolone other than recommendation. A mong remaining 112 patients, 67 (59.82\%) were male and $45(40.18 \%)$ were female. M ean age was 61.87 months. On admission, 88 patients $(78.57 \%)$ had been suffering from different types of infection, 26 (23.21\%) had multiple infections [Tables 1 and 2]. Most of the patients with infections were male $(59.09 \%)$ and most were under-6 years old $(67.04 \%)$. During prednisolone therapy, 33 patients $(29.46 \%)$ developed infections, $14(42.42 \%)$ had multiple infections [Tables 3 and 4 ]. M ost of the patients with infections were male $(63.64 \%)$ and most were under-6 years old (72.73\%). Pus cells (> 5 / HPF) in urine microscopy were found in 50 children (44.64\%). On urine culture, E. coli were found in eight $(7.14 \%)$, Pseudomonas in one $(0.89 \%)$ and Klebseilla in one $(0.89 \%)$ children. Total leucocyte count of $>$ $11000 /$ cumm was found in $49(43.75 \%)$, neutrophil count of $>$ $70 \%$ in $14(12.5 \%)$ and lymphocyte count $>60 \%$ in four (3.57\%) children. Bilateral \& right -sided consolidation were detected by chest X - ray in one case each $(0.89 \%)$. Bilateral, left $\&$ right -sided pleural effusion were diagnosed by chest $X$ ray in two $(1.78 \%)$, three $(2.68 \%)$ and one $(0.89 \%)$ cases respectively. Documented fever was found in eight (7.14\%) patients on admission and five (4.46\%) during prednosolone therapy.

Table 1: Types of infection found on hospital admission $(n=112)$

\begin{tabular}{lcr} 
Type & F requency & Percentage \\
\hline A cute respiratory infection & 60 & 53.57 \\
A cute watery diarrhea & 39 & 34.82 \\
U rinary tract infection & 10 & 7.14 \\
Cellulitis & 1 & 0.89 \\
Tuberculosis & 1 & 0.89 \\
Chicken pox & 1 & 0.89 \\
Scabies & 1 & 0.89 \\
Filariasis & 1 & 0.89
\end{tabular}

Table 2: Clinical presentations on admission related to infection ( $n=112$ )

$\begin{array}{lcr}\text { Clinical presentations } & \text { Frequency } & \text { Percentage } \\ \text { Fever } & 57 & 50.89 \\ \text { Cough } & 50 & 44.64 \\ \text { A bdominal pain } & 41 & 36.61 \\ \text { Loose motion } & 39 & 34.82 \\ \text { B reathing difficulty } & 18 & 16.07 \\ \text { Wheeze } & 17 & 15.18 \\ \text { Vomiting } & 12 & 10.71 \\ \text { Cold } & 9 & 8.03 \\ \text { Headache } & 3 & 2.68 \\ \text { Dysuria } & 1 & 0.89\end{array}$


Table 3: Types of infection developed during treatment with prednisolone $(n=112)$

\begin{tabular}{lcc} 
Type & Frequency & Percentage \\
\hline Oral thrush & 14 & 12.50 \\
Lower respiratory tract infection & 8 & 7.14 \\
Rhinitis & 5 & 4.46 \\
Chicken pox & 4 & 3.57 \\
A cute watery diarrhea & 2 & 1.78 \\
M umps & 2 & 1.78 \\
Scabies & 2 & 1.78 \\
Superficial fungal infection & 2 & 1.78 \\
A cute otitis media & 2 & 1.78 \\
A bscess & 2 & 1.78 \\
Dysentery & 1 & 0.89 \\
Pharyngitis & 1 & 0.89 \\
Cellulitis & 1 & 0.89 \\
Septicemia & 1 & 0.89
\end{tabular}

Table 4: Symptoms related to infection developed during treatment with prednisolone $(n=112)$

$\begin{array}{lcr}\text { Type } & \text { Frequency } & \text { Percentage } \\ \text { White spots in mouth cavity } & 14 & 12.50 \\ \text { Cough } & 8 & 7.14 \\ \text { Skin eruptions } & 6 & 5.36 \\ \text { Cold } & 5 & 4.46 \\ \text { Fever } & 5 & 4.46 \\ \text { Loose motion } & 2 & 1.78 \\ \text { Discharge from ear } & 2 & 1.78 \\ \text { Swelling around face } & 2 & 1.78 \\ \text { Blood in stool } & 1 & 0.89 \\ \text { Pain in throat } & 1 & 0.89 \\ \text { Wheeze } & 1 & 0.89 \\ \end{array}$

\section{DISCUSSION}

Different types of infection were detected in most nephrotic children at the time of admission and almost one third of patients suffered from new infections during treatment with steroid. ARI was the commonest infection in this study. Gulati et al. found urinary tract infection as the commonest one ${ }^{6}$. A recent study in Pakistan showed that ARI was the commonest infection in children with newly diagnosed primary nephrotic syndrome. ${ }^{1}$ Three studies from Iran, Taiwan \& Brazil also found similar result $t^{7-9}$. One study from India found it as the $3^{\text {rd }}$ most common infection ${ }^{10}$.
A cute watery diarrhea was found to be $2^{\text {nd }}$ most common infection (34.82\%) in our study. Similar result was observed in a study from Brazil. ${ }^{9}$ Study from Pakistan showed $11.6 \%$ cases of diarrhea associated with $\mathrm{NS}^{1}$.

UTI was the 3rd most common infection in this study. Two studies from India \& Nigeria found it as the most common infection and two studies from Pakistan \& Taiwan found it as the $2^{\text {nd }}$ most common infection ${ }^{1,8,10-11}$. Organisms causing UTI were almost similar to other studies though one study found staphylococcus aureus as the commonest organism ${ }^{1,9-11}$.

We found only one case of Tuberculosis. But two Indian studies found it as $2^{\text {nd }} \& 4^{\text {th }}$ most common infection $(10.4 \% \& 5 \%$ respectively $)^{6,10}$. This difference might be due to the fact that all cases were not screened for tuberculosis and high success rate of immunization in Bangladesh might influence the result.

Skin infection was found only in one patient in our study. But in India \& Iran, it was 5.2\%, 3.8\% \& 4.5\% respectively ${ }^{6-7,10}$.

One case of chicken pox was found in the present study. Similar finding was observed in some other studies abroad ${ }^{9-10}$.

Peritonitis was not detected in this study though many patients presented with abdominal pain, vomiting, loose motion etc. Peritonitis was found in different studies abroad ${ }^{1,6-10,12-13}$. Peritonitis is common in relapse cases, but we had studied only the $1^{\text {st }}$ attack of NS. This might be the reason that we did not face it.

$M$ eningitis was not found in our study though it is a recognized complication of NS. In two studies abroad, it was $0.64 \%$ \& $0.6 \%^{1,6}$. This might be due to small sample size in our study.

Some other infections like enteric fever, hepatitis, measles, osteomyelitis, herpetic infection etc. were not found in this study though observed in some other studies ${ }^{9-10,13-15}$.

Two most common presentations related to infection in this study were fever $\&$ cough which is similar to another study from Pakistan ${ }^{1}$.

Infections occurring during treatment with prednisolone were a bit different from initial infections. Some of these infections were related to prednisolone and some were hospital or community-acquired. We did not found any peritonitis during this period too though it was observed in some other studies ${ }^{13,16-17}$. This might be due to the fact that we did not analyze peritoneal fluid in all cases with abdominal pain and ascites.

\section{CONCLUSION}

Infection is very commonly associated with NS. So, it should be ruled out carefully in every case of NS at each visit and during management in hospital \& outside to reduce morbidity \& mortality. 


\section{REFERENCES}

1. M oorani K N, M ukesh R. Spectrum of infections in children with newly diagnosed primary nephrotic syndrome. Pak J M ed Res 2012; 51:10-14.

2. Eduardo HG. Effect of lipoid nephrosis cytokine on gl omerular sulfated compounds and al buminuria. Pediatr N ephrol 1995; 9:587-93.

3. Schnaper HW. Immunization practices in childhood nephrotic syndrome: a survey of North A merican pediatric nephrologists. Pediatr Nephrol 1994; 8:4-6.

4. Harris R C, Ismail N. Extrarenal complications of the nephrotic syndrome. A m J Kidney Dis 1994; 23:477-97.

5. $M C D$ onald $N E$, Wolfish $N, M$ claine $P$, Phipps $P$, Rossier $E$. Role of respiratory viruses in exacerbation of primary nephrotic syndrome. J Pediatr 1986; 108:378-82.

6. Gulati S, K her V, Gupta A, A rora P, Ray PK, Sharma RK. Spectrum of infections in Indian children with nephrotic syndrome. Pediatr Nephrol 1995; 9:431-4.

7. Safaei AASL \& M aleknejad S. Clinical and laboratoty findings and therapeutic responses in children with nephrotic syndrome. Indian J Nephrol 2010; 20: 68-71.

8. Wei C-C, Y U I-W, L in H-W, Tsai AC. Occurrence of infection among children with nephrotic syndrome during hospitalizations. Nephrology 2012; 17: 681-88.

9. Soeiro EM D, Koch VH, Fujimura M D, Okay Y. Influence of nephrotic state on the infectious profile in childhood idiopathic nephrotic syndrome. Rev. Hosp. Clin. Fac. M ed. S. Paulo 2004; 59(5): 273-78.

10. Senguttuvan $P, R$ avanan $K$, Prabhu N. Infections encountered in childhood nephrotics in a pediatric renal unit. Indian J Nephrol 2004; 14:85-88.

11. A deleke SI, A sani M O. U rinary tract infection in children with nephrotic syndrome in Kano, Nigeria. A nn A frican M ed 2009; 8(1): 38-41.

12. Elidrissy AT. Primary peritonitis and meningitis in nephrotic syndrome in Riyadh. Int J Pediatr Nephrol 1982; 3(1): 9-12.

13. Feldhoff $\mathrm{C}$, K leine $\mathrm{L}, \mathrm{Bachmann} \mathrm{H}$. Peritonitis and infection in children with idiopathic nephrotic syndrome. K lin Padiatr 1988; 200(1): 40-44.

14. Tain $Y L$, L in G, Cher TW. M icrobiological spectrum of septicemia and peritonitis in nephrotic syndrome. Pediatr N ephrol 1999; 13(9): 835-37.

15. A jayan $P, K$ rishnamurthy $S, B$ iswal $N, M$ andal J . Clinical spectrum and predictive risk factors of major infections in hospitalized children with nephrotic syndrome in southern India. Indian Pediatr 2013 [E-pub ahead of print].

16. Gorensek M J, L ebel M H, Nelson JD. Peritonitis in children with nephrotic syndrome. Pediatrics 1988; 81(6): 849-56.

17. K rensky A M, Ingelfinger JR, Grupe WE. Peritonitis in childhood nephrotic syndrome: 1970-1980. A m J Dis Child 1982; 136(8): 732-36. 